\title{
Yale University Offering an ONLINE COURSE: Autism and Related Disorders
}

\author{
Earn Yale College Credit or Sign Up for a NON-CREDIT (Audit) Experience
}

\section{Autism and Related Disorders \\ Yale Summer Session 2013}

PSYC S350E (30245)/CHLD S350E (30246)

Instructors:

Fred Volkmar M.D. Director of the Child Study Center, Yale University School of Medicine

James McPartland, Assistant Professor Child Study Center and Psychology, Yale University

Course Description:

Survey of current understandings and treatment of autism from infancy through adulthood. Topics include etiology, diagnosis and assessment, treatment and advocacy, and social neuroscience methods. Focus on ways in which research findings are integrated into diagnosis and treatment practices.

This course, now offered for over 25 years at Yale College, provides a comprehensive introduction to autism and related disorders. Topics covered include diagnosis and assessment, treatment, and selected topics in research with highly experienced and knowledgeable faculty. Those auditing the course will have access to the lecture portion of the course and will be able to listen to the discussion section. Participation should enhance the ability of educators and various professionals to provide higher levels of care to individuals with autism and their families.

About our online courses:

The online course format is similar to on campus courses with scheduled assignments for each week. Activities will include reading and written assignments as well as viewing of recorded lecture videos. The videos are recordings of on campus class lectures taught by the respective faculty member and can replayed as needed. In addition, students may participate in threaded discussion forums to begin dialog of subject matter. A central component to our courses is the live discussion sections each week with the faculty. They are real time sessions that allow the entire class to come together in a virtual meeting space (complete with audio and video) for discussion of class topics and office hours.

Taking a course online with Yale Summer Session led by Yale faculty will be a challenging and rewarding experience. Take advantage of small class sizes, live seminars and close interaction with your peers.

If you prefer an AUDITING experience, Select online courses are available for audit (non-credit). Auditing an online course allows the student to access and experience a Yale College course without being responsible for the completion of assignments. When auditing a course online you will have access to the same course site, course materials, and assignment instructions-if you wish to complete them - as the for-credit students. In addition, you will have access to your fellow auditors of the course for peer discussion and collaboration as well as the live discussion sections.

For more information please visit:

http://summer.yale.edu/find-your-program/online-courses 